\title{
Comparative Evaluation of Dentinal Microcracks in Root Canals Prepared by Neoniti, Reciproc, and ProTaper Instruments
}

\author{
Eshagh Ali Saberi ${ }^{1}$, Narges Farhad Mollashahi ${ }^{1}$ and Mahboobe Ahmadi ${ }^{2,{ }^{*}}$ \\ ${ }^{1}$ Department of Endodontics, Oral and Dental Diseases Center, Dental School, Zahedan University of Medical Sciences, Zahedan, Iran \\ ${ }^{2}$ Department of Endodontics, Dental School, Zahedan University of Medical Sciences, Zahedan, Iran \\ "Corresponding author: Department of Endodontics, Dental School, Zahedan University of Medical Sciences, Zahedan, Iran. Email: mahboobeahmadi1689@gmail.com
}

Received 2019 February 17; Revised 2019 June 01; Accepted 2019 June 12.

\begin{abstract}
Background: Biomechanical preparation of root canals is one of the most important stages in successful root canal treatment. Objectives: The aim of this study was evaluating and comparing dentinal micro cracks following root canal preparation with Neoniti, Reciproc, and ProTaper rotary systems.

Methods: Fifty mandibular first molars were selected and their distal roots were cut. The roots were randomly divided into three experimental groups of 15 and one control group consisting of 5 teeth. Defective specimens were excluded and replaced by sound molar teeth. A silicone-wash impression material was used to cover the root surface for simulating the PDL. The specimens were then prepared by Neoniti (25/0.08), Reciproc (25/0.08), and ProTaper rotary systems (up to the F3). The teeth in the control group remained unprepared. The specimens were then sectioned horizontally in of 3, 6, and $9 \mathrm{~mm}$ distances from the apex and explored by a stereomicroscope. Incidence of micro cracks formation were statistically analyzed by chi-square test.

Results: The intact specimens were free of cracks, but all root canals prepared with three different files had cracks. The frequency of micro cracks was observed in $46.7 \%, 40 \%$, and $20 \%$ of root canals following the preparation with Reciproc, Neoniti, and ProTaper files respectively. The cracks were in the middle thirds in teeth prepared by the Reciproc and ProTaper files and in the coronal and middle thirds in those prepared by the Neoniti file.
\end{abstract}

Conclusions: All Neoniti, Reciproc, and ProTaper systems create micro cracks in the root dentin. More cracks were observed in the Reciproc system.

Keywords: Dentinal Crack, Root Canal Preparation, Rotary Instrumentation System

\section{Background}

Canal preparation is one of the main steps in root canal treatment (1). With the advent of rotary files in recent years, the size and taper of the prepared canal have changed compared to manual files. The canal prepared with manual files is completely irregular, while that prepared with rotary files is rounder and smoother. Theoretically, the canal is prepared with a uniform taper by rotary files leading to more uniform distribution of stresses on the canal wall and increased resistance against root fracture (2). Despite their numerous advantages, rotary files exert a larger stress on the root canal walls than manual files. On the other hand, significantly more rotations in the canal which are necessary to complete shaping with rotary instruments as compared with hand files which may cause crack formation (3). Yoldas et al. reported the formation of more dentin micro cracks during canal preparation by rotary files than manual files (4). Liu et al. observed api- cal dentinal detachment in $2.5 \%$ of manual files and $21.9 \%$ of rotary files (5). Moreover, NiTi rotary instruments with different tip designs and various tapers and cutting blades lead to stress concentration in dentinal walls and may increase crack formation $(6,7)$. The tensile strength of dentin is $160 \mathrm{MPa}$, but rotary files generate a stress of 311 - $368 \mathrm{MPa}$ in the root dentin (8). Dentinal cracks and root fractures may appear when the tensile stress in the root canal walls exceeds the flexural strength of dentin (9).

Preparation taper is a factor predisposing the formation of dentinal defects so that the removal rate of dentin depends on the shape of the rotary file and its penetration rate. A larger removal rate of dentin results in a larger fracture rate. Niti rotary files with high taper cause dentinal crack formation in the dentin roots by increasing friction and stress inside the canal (10).

It is assumed that in comparison with full sequence systems, the use of a single file rotary instrument to prepare the whole canal may accumulate stress in the root 
canal space leading to a larger risk of dentinal cracks (11).

\section{Objectives}

To the best of our knowledge, there is no comparative study on the impact of single files with different kinematics and multi-file systems on the formation of dentinal cracks. Therefore, the aim of this study was to compare the Neoniti, Reciproc and ProTaper instruments on dentinal crack formation after root canal preparation of mesial roots of mandibular molars.

\section{Methods}

\subsection{Teeth Selection}

In this in-vitro study, 50 mandibular first molars with separate mesial and distal roots were selected. This study was approved by the Ethics Committee of Zahedan University of Medical Sciences (IR.ZAUMS.REC.1395.90). At first, teeth were examined radiographically and the teeth with completely formed roots, a root length of $20-22 \mathrm{~mm}$, and a root curvature of less than $20^{\circ}$ were included in this study. None of the teeth had signs of decay, root resorption, and calcification. The teeth with cracks, those with root surface defects or those fractured while preparing the cross sections were excluded.

\subsection{Tooth Preparation}

All tissue debris and plaques were removed from the root surface by manual curetting and subsequently immersing in 1.5\% hypochlorite (Bojneh Co. Iran) for $10 \mathrm{~min}$. After disinfection, the teeth were stored in normal saline. The distal root of the teeth were cut by diamond coated bur with air/water spray. Then all specimens were examined by stereomicroscopy (magnification: $12 \times$ ) to detect any possible fractures, craze lines, cracks, and surface defects. The specimens with defects were excluded and replaced by sound molar teeth.

The specimens were randomly divided into 3 experimental groups $(n=15)$ and a control group $(n=5)$. The access cavity was prepared using a diamond fissure, air/water spray, and a high-speed handpiece. Canal patency was performed and working length of the canal was determined by k-file 15 (Dentsply, Maillefer, Ballaelues, Switzerland) at a distance of $1 \mathrm{~mm}$ shorter than the anatomical apex. To stimulate PDL the silicon-wash impression material (Colten Whaledent AG Altsatten, Switzerland) was used. Therefore, the roots were placed in a 5.5 putty block (Altsatten, Switzerland).

\subsection{Root Canal Preparation}

The teeth in Group 1 were prepared by the ProTaper universal system (Dentsply Maillefer, Ballaelous, Switzerland). The canals were prepared coupled with reduction gear rotary handpiece driven with a VDW silver Reciproc electromotor (VDW Co, Munich, Germany) according to the manufacturer's instructions. First, the coronal region was prepared by SX file and then S1 and S2 were initially used with $300 \mathrm{rpm}$ and a torque of $3 \mathrm{~N} / \mathrm{cm}$ for flaring the coronal portion then $\mathrm{F} 1, \mathrm{~F} 2$ and $\mathrm{f} 3$ were used to the working length with light pecking and in and out motion.

The teeth in group 2 were prepared by the Reciproc R25 system (VDW, Munich, Germany) with the File 25/0.08 according to the manufacturer's instructions at $350 \mathrm{rpm}$ and a torque of $4 \mathrm{~N} / \mathrm{cm}$ with in and out motion in the "Reciproc ALL" Program to reach the working length.

The specimens in Group 3 were prepared by the Neoniti A1 system (Sjoding Sendoline, Kista, Sweden) with a single file $25 / 0.08$ at $350 \mathrm{rpm}$ and a torque of $1.5 \mathrm{~N} / \mathrm{cm}$.

In group 4 (control group) the tooth left unprepared.

To prepare the canal through all the above methods, the canals were washed with $12 \mathrm{~mL}$ of $1.5 \%$ sodium hypochlorite. All specimens were cut 3, 6, and $9 \mathrm{~mm}$ distance from the apex by a low-speed saw (Isomet: Buehler Ltd. Lake Bluff.IL) under water spray as coolant. The samples were observed by a digital stereomicroscope (Olympus BX43). At a $12 \times$ magnification and images were taken. A total number of 45 images were taken from specimens in each group for examining the presence or absence of cracks. Two different groups were considered for crack definition (crack and no crack). To prevent confusion, noncrack was defined as dentin free of cracks and craze lines on the inner and outer surfaces of the root. In contrast, crack was defined as any line extending from the lumen inside the canal along the dentin thickness or from the outer surface of the root into dentin.

\subsection{Data Analysis}

Chi-square test was used to find significant differences in crack incidence between the study groups. Statistical analysis was performed using SPSS 20 software (SPSS Inc, Chicago, IL).

\section{Results}

Table 1 shows the distribution of dentinal defects in each group. All NiTi files significantly cause more dentinal defects compared to the control group $(\mathrm{P}<0.05)$.

No statistically significant difference was found between the NiTi files in terms of crack formation $(\mathrm{P}=0.283)$. However, more cracks were formed in the Reciproc file than other files. 
Table 1. Distribution of Dentinal Defects in Different Root Canal Preparation Systems $(\mathrm{P} \text { Value }=0.283)^{\mathrm{a}}$

\begin{tabular}{lcccc}
\hline & \multicolumn{2}{c}{ Absolute Number of Cracks, mm } & $\begin{array}{c}\text { Total Cracked, } \\
\text { Roots Per Group }\end{array}$ \\
\cline { 2 - 3 } & $\mathbf{3}$ & $\mathbf{6}$ & $\mathbf{9}$ & $0(0)$ \\
\hline Control & $0(0)$ & $0(0)$ & $0(0)$ & $3(20)$ \\
\hline ProTaper & $0(0)$ & $3(20)$ & $0(0)$ & $7(46.7)$ \\
\hline Reciproc & $0(0)$ & $7(46.7)$ & $0(0)$ & $6(40)$ \\
\hline Neoniti & $0(0)$ & $5(33.3)$ & $1(6.66)$ & \\
\hline
\end{tabular}

${ }^{\mathrm{a}}$ Values are expressed as No. (\%).

\section{Discussion}

According to the results, all instrumentation systems cause dentinal cracks regardless of file kinematics (full rotation or reciprocation). Previous studies have shown that different instrumentation and obturation techniques lead to dentinal cracks $(7,12)$. The difference between canal preparation instruments in terms of micro crack formation can be attributed to the difference in cross sections design and canal preparation techniques. The Reciproc file has an S-shaped cross-section with sharp cutting edges, while the ProTaper file has a triangular cross-section or a modified triangular cross-section with less cutting efficiency and smaller space for accumulation of debris (13). Despite the lack of a significant difference between different instruments, the reciprocation system creates more dentinal cracks than other systems. It has been reported that the reciprocal motion exerts a greater torsional force to the canal walls with a larger apical debris extrusion (14, 15).

Based on the results, the Neoniti A1 system ranks second after the Reciproc files in terms of crack formation. The large number of cracks in this system can be attributed to much more stress being imposed to dentinal walls primarily due to its high tapering. The mesial root of the mandibular first molar has a thin canal and the use of the Neoniti A1 file with a taper of $8 \%$ may cause more stress concentration resulting in the formation of micro cracks. On the other hand, this file is manufactured by EDM (electric discharge machining) process with a rough surface resulting in more crack formation (16).

According to Loizides et al., the ProTaper forms a sufficiently rounded cross section in the canal which may cause a uniform stress distribution along the canal and increased resistance against root fracture (17). The frequency of cracks in the ProTaper file is lower than other files. Preparation of a larger apical size (F3 30/0.09) by the ProTaper system can increase the stress on the canal wall and thereby crack formation, but the system has a convex triangular or modified triangular cross-sectional area which reduces its cutting efficacy. On the other hand, the prepa- ration of the coronal region of the canal may reduce stress while preparing the apical region of the canal leading to less dentin defects. Some studies suggest an increase in crack development in the crown-down technique $(7,18)$. While the single length technique is used in the ProTaper system.

All cracks were formed in the middle thirds and coronal third by the Neoniti A1 and middle third by Reciproc files. According to Ustun et al., the Reciproc system results in crack formation in the coronal and middle thirds without any crack in the apical level which is somewhat consistent with our results (19). However, Gergi et al. found cracks in the apical and middle thirds (20). According to the results, the ProTaper system produces cracks in the middle third. Ustun et al. found cracks in the coronal, middle and apical thirds produced by the ProTaper system (19).

In a study by Jalali et al., the Reciproc system produced less cracks in the root canal wall than the ProTaper rotary systems (11). The occurrence of micro cracks in the Liu et al. study was reported 50\% for proTaper and 5\% for Reciproc. The frequency of cracks in the Reciproc system was greater than that of the ProTaper system in this study. This difference can be related to the amount of dentin removed from the canal wall. Despite flexural and rotary stresses to the dentin by the Reciproc motion, the single Reciproc files with greater taper may cause crack formation (21). According to the literature, single file systems can exert more stress than full-sequence systems. A larger stress concentration may in turn lead to micro crack formation (22). On the other hand, single files are 4 times faster than rotary files for instrumentation, and micro crack formation increases with increasing speed and torque $(13,23)$.

In general, micro crack formation depends on the cross-section design of the file, the final size of the canal preparation and preparation technique (24).

According to literature, factors such as age and dehydration may cause crack formation (25). Regardless of instrumentation stages, the stress to the root dentin increases with teeth dehydration (26). On the other hand, extraction time, storage condition, tooth length, canal shape, and canal volume affect the results (27). Considering the impact of the volume of root canal space, the use of CBCT before treatment for measuring the mesiodistal and buccolingual dimensions of the canal and standardization of canal shape and volume are recommended to be further investigated in future studies.

\subsection{Conclusions}

The ProTaper, Reciproc, and Neoniti files caused micro crack formation in the root canal. Despite the lack of a significant statistical difference between the three systems with different kinematics, the single file reciprocating sys- 
tems caused more micro crack formation than single and full sequence rotary systems.

\section{Acknowledgments}

The authors wish to thank the Deputy of Research and Information Technology for financial support of this research.

\section{Footnotes}

Conflict of Interests: The authors deny any conflicts of interest related to this study.

Ethical Approval: This study was approved by the Ethics Committee of Zahedan University of Medical Sciences (code is IR.ZAUMS.REC.1395.90).

Funding/Support: The manuscript has been funded by Zahedan University.

\section{References}

1. Hegde MN, Shetty S, Godara N. Evaluation of fracture strength of tooth roots following canal preparation by hand and rotary instrumentation-An in vitro study. Endodontology. 2008;20(1):22-9.

2. Sathorn C, Palamara JE, Messer HH. A comparison of the effects of two canal preparation techniques on root fracture susceptibility and fracture pattern. J Endod. 2005;31(4):283-7. doi: 10.1097/01.don.0000140580.03121.61. [PubMed: 15793385].

3. Milani AS, Froughreyhani M, Rahimi S, Jafarabadi MA, Paksefat S. The effect of root canal preparation on the development of dentin cracks. Iran Endod J. 2012;7(4):177-82. [PubMed: 23130076]. [PubMed Central: PMC3487527].

4. Yoldas O, Yilmaz S, Atakan G, Kuden C, Kasan Z. Dentinal microcrack formation during root canal preparations by different NiTi rotary instruments and the self-adjusting file. J Endod. 2012;38(2):232-5. doi: 10.1016/j.joen.2011.10.011. [PubMed: 22244643].

5. Liu R, Kaiwar A, Shemesh H, Wesselink PR, Hou B, Wu MK. Incidence of apical root cracks and apical dentinal detachments after canal preparation with hand and rotary files at different instrumentation lengths. J Endod. 2013;39(1):129-32. doi: 10.1016/j.joen.2012.09.019. [PubMed: 23228272].

6. Blum JY, Machtou P, Ruddle C, Micallef JP. Analysis of mechanical preparations in extracted teeth using ProTaper rotary instruments: value of the safety quotient. J Endod. 2003;29(9):567-75. doi: 10.1097/00004770-200309000-00007. [PubMed: 14503829].

7. Shemesh H, Bier CA, Wu MK, Tanomaru-Filho M, Wesselink PR. The effects of canal preparation and filling on the incidence of dentinal defects. Int Endod J. 2009;42(3):208-13. doi: 10.1111/j.13652591.2008.01502.x. [PubMed: 19228210].

8. Kim HC, Lee MH, Yum J, Versluis A, Lee CJ, Kim BM. Potential relationship between design of nickel-titanium rotary instruments and vertical root fracture. J Endod. 2010;36(7):1195-9. doi: 10.1016/j.joen.2010.02.010. [PubMed: 20630298].

9. Nair PN, Sjogren U, Krey G, Kahnberg KE, Sundqvist G. Intraradicular bacteria and fungi in root-filled, asymptomatic human teeth with therapy-resistant periapical lesions: A long-term light and electron microscopic follow-up study. J Endod. 1990;16(12):580-8. doi: 10.1016/S0099-2399(07)80201-9. [PubMed: 2094761].

10. Shemesh H, Roeleveld AC, Wesselink PR, Wu MK. Damage to root dentin during retreatment procedures. J Endod. 2011;37(1):63-6. doi: 10.1016/j.joen.2010.10.002. [PubMed: 21146079].
11. Jalali S, Eftekhar B, Paymanpour P, Yazdizadeh M, Jafarzadeh M. Effects of Reciproc, Mtwo and ProTaper instruments on formation of root fracture. Iran Endod J. 2015;10(4):252-5. doi: 10.7508/iej.2015.04.009. [PubMed: 26523141]. [PubMed Central: PMC4609664].

12. Bier CA, Shemesh H, Tanomaru-Filho M, Wesselink PR, Wu MK. The ability of different nickel-titanium rotary instruments to induce dentinal damage during canal preparation. J Endod. 2009;35(2):2368. doi: 10.1016/j.joen.2008.10.021. [PubMed: 19166781].

13. Burklein S, Hinschitza K, Dammaschke T, Schafer E. Shaping ability and cleaning effectiveness of two single-file systems in severely curved root canals of extracted teeth: Reciproc and WaveOne versus Mtwo and ProTaper. Int Endod J. 2012;45(5):449-61. doi: 10.1111/j.13652591.2011.01996.x. [PubMed: 22188401].

14. Burklein S, Schafer E. Apically extruded debris with reciprocating single-file and full-sequence rotary instrumentation systems. J Endod. 2012;38(6):850-2. doi: 10.1016/j.joen.2012.02.017. [PubMed: 22595125].

15. Burklein S, Tsotsis P, Schafer E. Incidence of dentinal defects after root canal preparation: Reciprocating versus rotary instrumentation. J Endod. 2013;39(4):501-4. doi: 10.1016/j.joen.2012.11.045. [PubMed: 23522545].

16. Gupta R. A new approach to single file endodontics: Neoniti rotary file system. Int J Adv Case Rep. 2015;2(21):1255-7.

17. Loizides AL, Kakavetsos VD, Tzanetakis GN, Kontakiotis EG, Eliades G. A comparative study of the effects of two nickel-titanium preparation techniques on root canal geometry assessed by microcomputed tomography.JEndod.2007;33(12):1455-9. doi:10.1016/j.joen.2007.07.019. [PubMed: 18037058].

18. Capar ID, Arslan H, Akcay M, Uysal B. Effects of ProTaper universal, ProTaper next, and HyFlex instruments on crack formation in dentin. J Endod. 2014;40(9):1482-4. doi: 10.1016/j.joen.2014.02.026. [PubMed: 25146038].

19. Ustun Y, Aslan T, Sagsen B, Kesim B. The effects of different nickeltitanium instruments on dentinal microcrack formations during root canal preparation. Eur J Dent. 2015;9(1):41-6. doi: 10.4103/13057456.149638. [PubMed: 25713483]. [PubMed Central: PMC4319298].

20. Gergi RM, Osta NE, Naaman AS. Dentinal crack formation during root canal preparations by the twisted file adaptive, Reciproc and WaveOne instruments. Eur J Dent. 2015;9(4):508-12. doi: 10.4103/13057456.172634. [PubMed: 26929688]. [PubMed Central: PMC4745231].

21. Pedulla E, Grande NM, Plotino G, Gambarini G, Rapisarda E. Influence of continuous or reciprocating motion on cyclic fatigue resistance of 4 different nickel-titanium rotary instruments. J Endod. 2013;39(2):258-61. doi: 10.1016/j.joen.2012.10.025. [PubMed: 23321241].

22. Priya NT, Chandrasekhar V, Anita S, Tummala M, Raj TB, Badami V, et al. "Dentinal microcracks after root canal preparation" a comparative evaluation with hand, rotary and reciprocating instrumentation. J Clin Diagn Res. 2014;8(12):ZC70-2. doi: 10.7860/JCDR/2014/11437.5349. [PubMed: 25654036]. [PubMed Central: PMC4316342].

23. Gavini G, Caldeira CL, Akisue E, Candeiro GT, Kawakami DA. Resistance to flexural fatigue of Reciproc R25 files under continuous rotation and reciprocating movement. J Endod. 2012;38(5):684-7. doi: 10.1016/j.joen.2011.12.033. [PubMed: 22515903].

24. Saberi EA, Mohammadi A, Ebrahimipour S, Baniasadi S. In-vitro comparison of NiTi Tee, RaCe and protaper instruments in dentinal crack formation.J Dent Mater Tech. 2017;6(4):152-8.

25. Bajaj D, Sundaram N, Nazari A, Arola D. Age, dehydration and fatigue crack growth in dentin. Biomaterials. 2006;27(11):2507-17. doi: 10.1016/j.biomaterials.2005.11.035. [PubMed: 16338002].

26. Shemesh H, Lindtner T, Portoles CA, Zaslansky P. Dehydration induces cracking in root dentin irrespective of instrumentation: A twodimensional and three-dimensional study. J Endod. 2018;44(1):120-5. doi: 10.1016/j.joen.2017.07.025. [PubMed: 29079053].

27. Cobankara FK, Ungor M, Belli S. The effect of two different root canal sealers and smear layer on resistance to root fracture. $J$ Endod. 2002;28(8):606-9. doi: 10.1097/00004770-200208000-00011. [PubMed: 12184425]. 